\title{
High Performance Liquid Chromatography Method to Detect Tramadol and Sildenafil in the Blood of Rats on Combination Treatment.
}

\author{
Rabie S. Farag ${ }^{1}$,Mohamed El Nawawy ${ }^{1}$,Wael M. Fathy ${ }^{2}{ }^{*}$, Hamada Atiaa $^{2}$, and Tarek \\ Mahdy ${ }^{2}$ \\ ${ }^{1}$ Chemistry department,Faculty ofScience, Al-Azhar University, Cairo, Egypt and \\ ${ }^{2}$ Analytical Toxicology Laboratory, Forensic Medicine Authority, Cairo, Egypt.
}

\begin{abstract}
Tramadol is one of widest abused street drug in Egypt. Recently, drug abusers were taking tramadol beside sildenafil for sexual purposes.So it was important to develop a newHPLC method for the simaultineous determination of tramadol andSildenafil in the blood of rats exposed to a combination of specific dose of tramadol and sildenafil. Sample preparation involved liquid-liquid extraction with methyl tertiary butyl ether (MTBE) and backextraction with hydrochloric acid.Tramadol,sildenafiland the internalstandardnalbuphine were separated by reversed phaseHPLCusing60\%acetonitrileand $40 \% 20 \mathrm{mMsodium}$ phosphate bufferpH 7.5 . Detection was by using UV at wavelengths $230 \mathrm{~nm}$. The method was linear fortramadol $(0.8-100 \mathrm{ug} / \mathrm{ml})$ and Sildenafil $(0.3-100 \mathrm{ug} / \mathrm{ml})$ with mean recoveries of $97.2 \%$ and $100.8 \%$, respectively. Intra- and inter-day precisionswere $9.34 \%$ and $9.12 \%$ for tramadol and $11.82 \%$, and $10.43 \%$ for sildenafilat the respective limits of quantitation $(0.8$ and $0.3 \mathrm{ug} / \mathrm{ml})$. Accuracy fortramadol and Sildenafil ranged from $96.6 \%$ to $97.8 \%$ and $99.2 \%$ to $101.3 \%$ respectively. The method was applied to apharmacokinetic study of tramadol and sildenafil in rats.
\end{abstract}

Key words: hplc, Tramadol, Sildenafil.

\section{Council for Innovative Research}

Peer Review Research Publishing System

Journal: INTERNATIONAL JOURNAL OF COMPUTERS \& TECHNOLOGY

Vol 11, No. 6

editor@cirworld.com

www.cirworld.com, member.cirworld.com 


\section{Introduction}

Tramadol hydrochloride, ( \pm )-Trans-2-[(dimethylamino)methyl]-1-(3-methoxyphenyl) cyclohexanol (Fig. 1a), is acentrallyacting analgesic used in the treatment of mild tomoderate pain (1). Its therapeutic plasma concentration range is $100-300$ $\mathrm{ng} / \mathrm{ml}$ (2). Tramadol is rapidly and almostcompletely absorbed after oral administration but its absolutebioavailability is only 65-70\% due to first-pass metabolism (3).The metabolism of tramadol in human is mediated bycytochrome P4502D6 (CYP2D6) to O-desmethyltramadolODT) and $\mathrm{N}$-desmethyltramadol (NDT). ODT ispharmacologically active and contributes to the analgesic efficacyof tramadol (4).

Sildenafil ( 1- [[ 3 - ( 6,7 - dihydro - 1- methyl - 7 oxo - 3- propyl - 1H-pyrazolo [ 4,3-d] pyrimidine - 5 -yl ) - 4 - ethoxyphenyl ] sulfonyl ] - 4- methyl piperazine (fig. $1 \mathrm{~b}$ ) is a potent and selective inhibitor of cGMP - specific phosphodiesterase capable of enhencing the relaxation of the penile corpus covernosum and therefore having the potential improve penile erectile function. Quantification of sildenafil is essential during the evaluation of drug. Several HPLC methods have been developed for determination of sildenafil in various samples, such as dietary supplements (5-7), pharmaceutical preparation (8), and mouse skin (9), human plasma and urine $(10,11,12)$. For a review see "Sildenafil determination in various matrices" (13) Analyses were based on liquid-liquid extraction at basic $\mathrm{pH}(6,7)$. For this purpose we used this simple, rapid and accurate HPLC method.

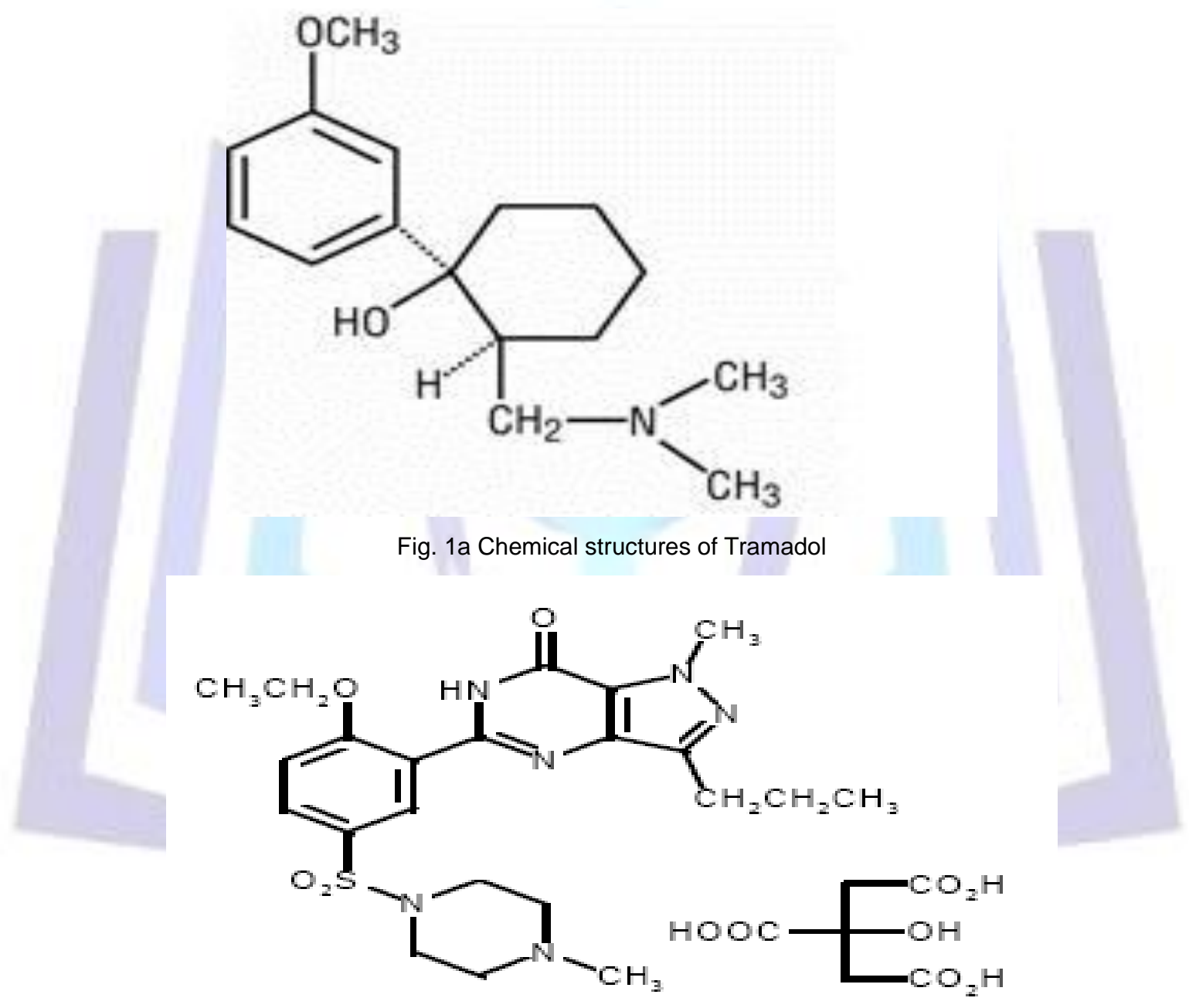

Fig. 1bChemical structures ofSildenafil

\section{Experimental}

\section{Chemicals and reagents}

Pure Tramadol hydrochloridewas obtained from. Minapharm, Cairo, Egypt, Sildenafil citrate was obtained from Pfizer pharmaceutical company (Pfizer Ltd., Egypt),and Nalbuphine was obtained from AmounPharmaceuticalCo.El-ObourCity (Cairo-Egypt). Acetonitrile,Methanol and methyl tertiary butyl ether (MTBE) (HPLC grade) were purchased from Merck(Darmstadt, Germany). Deionized water was produced bya Milli-Q Millipore Water System (Milford, MA). Potassiumdihydrogen phosphate and sodium tetraborate decahydratewere from J.T. Baker (Deventer, Holland). All other reagents and materials were of analyticalgrade and supplied from commercial sources. The aqueous andorganic 
components of the mobile phase, degassed under pressure,were mixed by the HPLC. The LC mobile phases were filteredthrough 0.2-mm cellulose acetate membrane filters(Sartorius Stedim Biotech S.A.; Aubagne Cedex, France) with asolvent filtration apparatus.

\section{Standard solutions}

Stock solutions of Tramadol, sildenafil and the internal standard nalbuphinewereprepared to a concentration of 1,000 $\mu \mathrm{g} / \mathrm{mL}$ in $\mathrm{MeOH}$ usingvolumetric flasks. These were then stored at $-20 \mathrm{C}$. To obtaina final concentration of $100 \mu \mathrm{g} / \mathrm{mL}$, appropriate dilutions ofstock standard solutions were prepared by diluting $1 \mathrm{~mL}$ ofeach solution to $10 \mathrm{~mL}$. These solutions of Tramadol, sildenafil and the internal standard nalbuphine were serially diluted in glass tubes (10 $\mathrm{mL})$ to reachfinal concentrations of $5,1,0.5$ and $0.1 \mu \mathrm{g} / \mathrm{mL}$. Then they werestored at $-20 \mathrm{C}$.

\section{Instrumentation and chromatographic conditions}

HPLC was performed an Agilant (USA) series1100 Quadrapump and Diode Array DETECTION. C18 5 $\mu \mathrm{m}$ Ecilpse $\times$ DB column with particle size $5 \mu \mathrm{m}(150 \times 4.6 \mathrm{~mm})$ was use. The mobile phase consisted of $60 \%$ acetonitrile $(\mathrm{A})-40 \% 20 \mathrm{Mm}$ $\mathrm{KH} 2 \mathrm{PO} 4$ buffer (B) adjusted to $\mathrm{pH} 7.5$ with $\mathrm{NaOH}$ at a flow rateof $1.5 \mathrm{~mL} / \mathrm{min}$.

\section{Animal treatment and sampling}

Animal experiments were conducted at the animal experimentalfacility of the national researchcenter (Cairo-Egypt).Twenty fourWistar breed rats weighing 130 to $150 \mathrm{~g}$ were usedfor the experiment. The rats were randomly divided into eight groups consisting of three animals. These rats were housedtwo per cage, under conventional ventilation, temperature (18$20^{\circ} \mathrm{C}$ ) and lighting (16 h light/day) conditions. During thestudy, they were given free access to water and food. Thehealth of the rats was monitored daily by qualified personnelsupervised by aveterinarian for the duration of the study. Theanimals were given one week to adjust to their newenvironment before commencement of the experiment.During this adjustment period; all animals were kept on drugfreefeed. After the adjustment period, Group GI received asingle injection of saline while the other groups received acombination of Tramadol at $100 \mathrm{mg} / \mathrm{kg}$ and Sildenafil at $100 \mathrm{mg} / \mathrm{kg}$; allinjections were given orally. The animal groupswere sacrificed after $30 \mathrm{~min}$ (GII), 1h (GIII), 2 (GIV), $4 \mathrm{~h}$ (GV), $6 \mathrm{~h}(\mathrm{GVI}), 9 \mathrm{~h}$ (GVII) and $24 \mathrm{~h}$ (GVIII), respectively, following administration.

The animals were decapitated and the bloodsamples collected immediately. All samples were immediately frozen at-20 ${ }^{\circ} \mathrm{C}$ until analysis .

\section{Sample extraction}

The procedure was performed in a $15-\mathrm{mL}$ screw-capped polypropylenevial. A $1-\mathrm{mL}$ aliquot of whole blood was added to $300 \mu \mathrm{L}$ of IS $(100 \mu \mathrm{g} / \mathrm{mL})$. After vortexing for $30 \mathrm{~s}, 0.5 \mathrm{~mL}$ ofNa2B4O7 $10 \mathrm{H} 2 \mathrm{O}$ buffer $(0.2 \mathrm{M}, \mathrm{pH} 9.0)$ was added and thesample was vortexed again. Six $\mathrm{mL}$ of MTBE was then added,then the sample was vortexed (30 s), shaken (60 osc/min,10 $\mathrm{min}$ ) and centrifuged at 2,191 g (rotor radius $10 \mathrm{~cm}$ ) for $10 \mathrm{~min}$. Five $\mathrm{mL}$ of the supernatant was collected in a cleanscrew-cappedpolypropylene vial containing $1 \mathrm{~mL}$ of $0.01 \mathrm{MHCl}$. This latter blend was vortexed (30 s), shaken (60 $\mathrm{osc} / \mathrm{min}, 5 \mathrm{~min}$ ) and centrifuged at 2,191 $\mathrm{g}$ (rotor radius $10 \mathrm{~cm}$ ) for5 $\mathrm{min}$. The organic layer was discarded. The aqueous layer wasalkalinized with $0.5 \mathrm{~mL}$ of $0.2 \mathrm{M}$ borate buffer and the mixturewas extracted with $5 \mathrm{~mL}$ of MTBE by shaking for 5 min followedby centrifugation at 2,191 g (rotor radius $10 \mathrm{~cm}$ ) for $3 \mathrm{~min}$. Four $\mathrm{mL}$ of organic layer was transferred to a 5-mL glasstube for complete evaporation in speed vacuum concentrator. The residue was reconstituted with $500 \mu \mathrm{L}$ of amobile phase of acetonitrile-Phosphate buffer (10:90) and $100 \mu \mathrm{L}$ was injected onto the HPLC.

\section{Bioanalytical method validation}

The described method was validated in terms of linearity, limitof detection (LOD), limit of quantification (LOQ), recovery,specificity, stability, precision and accuracy according to internationalguidelines on the bioanalytical method validation (14).Calibration curves were obtained by spiking the blank matrixwith a known concentration of each drug and Internal standard to provideconcentrations of 2.5, 5, 10,30,50, 70 and $100 \mu \mathrm{g} / \mathrm{mL}$. The calibration curves of peak area versus concentration $(\mu \mathrm{g} / \mathrm{mL})$ of the investigated drugs were plotted. Least squares regressionparameters for the calibration curves were calculated, and theconcentrations of the test samples were interpolated from theregression parameters. Sample concentrations were determinedby linear regression, using the formula $Y=m X+b$, where Ypeak area, $X$ concentration of the standard in $\mathrm{mg} / \mathrm{mL}$, mthe slope of the curve and $b$ the intercept with $Y$ axis. Correlation coefficients for each of the calibration curves were. 0.997Within-run and between-run accuracy and precision wereassessed on quality control samples (QC samples) and determinedby replicate analysis using seven determinations of differentconcentration levels: LOQ $(0.8 \mu \mathrm{g} / \mathrm{mL} ; 0.3 \mu \mathrm{g} / \mathrm{mL}$ for Tramadol and sildenafil), low QC (2.5 and $5 \mu \mathrm{g} / \mathrm{mL})$, medium QC $(10$ and $30 \mu \mathrm{g} / \mathrm{mL})$ and high QC $(100 \mu \mathrm{g} / \mathrm{mL})$.

\section{Quantification}

When unknown samples were assayed, a control and a fortifiedblank sample were processed simultaneously for qualitycontrol. LODs and LOQs were determined as analyte concentrationsgiving signal-to-noise ratios of 3 and 10 , respectively. 


\section{Statistical analysis and pharmacokinetic analysis}

The statistical analyses were evaluated using an analysis of variance (ANOVA) test. The results were presented as mean \pm standard deviation (SD). All the analyses were conducted using GraphPad InStat (GraphPad Software; La Jolla, $\mathrm{CA})$. For all the experiments, differences were considered significant if the associated probability level (P) was lower than 0.05. The pharmacokinetic calculations were carried out using WinNonLin v 5.2.1 (Pharsight Corp.; Sunnyvale, CA). Maximum concentration(Cmax) for all the investigated drugs in blood and the time required to reach Cmax (Tmax) were predicted from the data. Changes in blood concentrationsfor all the investigated drugs were evaluated using the standard non-compartmental analysis and the relative pharmacokinetic parameters were determined using standardoncompartmentalequations.

\section{Results and Discussion}

\section{Detection method development}

The mobile phase was chosen on the basis of a previously published method. The Phosphate buffer was tested at different concentrations $(0.01,0.02,0.05$ and $0.1 \mathrm{M})$. At the lower concentration, $\mathrm{Tr}$ and IS resulted in the same retention time. The investigated drugs were well separated from blood impurities at buffer concentrations of $0.02,0.05$ and $0.1 \mathrm{M}$, and $0.02 \mathrm{M}$ was chosen as optimal because higher concentrations can cause salt precipitation in the HLPC. A range of buffer $\mathrm{pH}$ (3.0 to 8 ) was assayed to optimize the chromatographic separation. Optimal peak separation for pure investigated drugs was produced using a $\mathrm{pH}$ ranging between 7 and 8 , but the actual working is $\mathrm{pH} 7.5$. The final mobile phase resulted in acetonitrile-NaH2PO4 $(0.02 \mathrm{M}), \mathrm{pH} 7.5$ with a $1.5 \mathrm{~mL} / \mathrm{min}$ flow rate. This was found to be an excellent compromise in terms of sensitivity and peak separation. The wavelengths tested in the present study were: $275 \mathrm{~nm}(15)$ ,225 nm (16) and $290 \mathrm{~nm}$ (17). The wavelength value of $230 \mathrm{~nm}$ was found to beoptimal in terms of sensitivity for all the investigated drugs and avoidingseveral matrix impurities that became problematic at lowerwavelengths.

The Internal standard was chosen based on previous studies on Tramadol.

\section{Optimization of the extraction condaitions}

The influence of the kind of solvents (an important tool for the selectivity of the method) was studied to find the optimal extraction protocol for the investigated drugs. The solvents ethylacetate $(20,18)$, MTBE (19) and chloroform (commonly used in the Forensic Toxicology Lab; Cairo, Egypt) were compared. MTBE was selected as the most suitable organic solvent in terms of analyte extraction and minimization of matrix interference (Table I). Optimal pH value for extraction was 9.

\section{Table I}

Single Extraction Recovery Percent $( \pm S D)$ of Tramadol, sildenafil and IS Spiked at $20 \mu \mathrm{g} / \mathrm{mL}$ with Different Organic Solvents $(n=3)$

\begin{tabular}{|l|l|l|l|}
\hline Organic solvents & Tramadol & sildenafil & IS \\
\hline Ethylacetate & $85.1 \pm 5.4$ & $76.5 \pm 6.4$ & $25.2 \pm 2.4$ \\
\hline Chloroform & $80.4 \pm 4.4$ & $45.3 \pm 3.7$ & $81.1 \pm 5.2$ \\
\hline MTBE & $97.2 \pm 6.39$ & $100.8 \pm 5.33$ & $99.8 \pm 3.5$ \\
\hline
\end{tabular}

\section{Method validation}

It was found that there were no published methodologies for simultaneous determination of Tramadol, Sildenafil and Intrnal standard from rat blood samples using HPLC-UV, so it was necessary to validate each step of the suggested analytical method. The calibration curves were constructed by plotting the ratioof the peak areas versus concentrations in the working range.Good linearity was achieved for Tramadol and sildenafil in therange studied. The linear regression equations are reported inTable II.According to Europea Medicine Evaluation Agency (EMEA) guidelines (14), LODs and LOQs were calculated based on a signal-to-noise approach. These calculationswere performed by comparing measured signals fromsamples with known low concentrations of investigated drugs with thoseof blank samples. In this way, the minimum concentration atwhich the investigated drugs can be reliably quantified (LOQ) or detected(LOD) was determined. The typical signal-to-noise ratios were $10: 1$ and 3:1 for LOQ and LOD, respectively (Table II). Boththe accuracy and the precision of these values lay within theproposed criteria [relative standard deviation (RSD), 20\%].Specificity and interference by co-eluting components weredetermined by comparing the chromatograms of differentbatches of blank matrices to those from spiked whole bloodand test samples. It was found that under optimized chromatographicconditions, peaks due to the matrix did not interferewith Tramadol sildenafil and IS. Typical retention times forTramadol, sildenafil and IS were $2.8+0.2,1.7+0.05$ and $2.2+0.05 \mathrm{~min}$, respectively (Figures $2 \mathrm{~A}, 2 \mathrm{~B}$ and $2 \mathrm{C}$ ). Recoveries were $97.2 \pm 6.39 \%$ for Tramadol, $100.8 \pm 5.33 \%$ forsildenafil and $99.8 \pm 3.5 \%$ for IS. The respective coefficient of variation (CV) (\%) values variedfrom 3.48to9.34, 5.33to11.82 and1.06 to 4.41 for Tramadol, sildenafil and IS, respectively. Intra-dayvalue consistency (repeatability) was evaluated for five replicatesof each QC sample during the same day. Inter-day valueconsistency (intermediate precision) was evaluated by quantizationof Tramadol, sildenafil and IS in QC samples on five differentdays. Relative errors for both the intra-day and inter-dayaccuracy were, $7 \%$.Stability studies were performed 
to ensure good reproducibilityof the method. Stock solutions of the investigated drugs and IS $(10 \mu \mathrm{g} / \mathrm{mL})$ and high and low QC samples were tested for stabilityunder short-term room temperature conditions, longtermstorage conditions $\left(-20^{\circ} \mathrm{C}\right)$ and freeze-thaw treatment. Tramadol ,sildenafiland IS were very stable at both $20^{\circ} \mathrm{C}$ for $24 \mathrm{~h}$ and-20 $\mathrm{C}$ for 30 days. Data obtained after three freeze-thaw cycles showed that the investigated drugswere stable in rat blood (CV, 7\%). These findingsindicated that the storage of investigated drugs in blood samples at $-20^{\circ} \mathrm{C}$ is adequate, and no stability-related problems would beexpected during routine analyses for analytical studies within10 days.Robustness of the methodology was determined by the reproducibility of results using the (analytical) method in $20^{\circ} \mathrm{C}$; a loss of $10-12 \%$ was observed anddifferent laboratories or under different circumstances. Thepresent study evaluated three blood aliquots from the treatedrats in two different labs (Faculty of science, Al-AzharUniversity, andChemistry Lab., Forensic Medicine Authority,Cairo, Egypt.) andobtained variations of less than $7.2 \%$. These results demonstrate that the method enables accuratequantification of Tramadol and sildenafil. The validation parameterswere in agreement with the EMEA guidelines (14).Although to the best of our knowledge, no simultaneous detectionof, Tramadol and sildenafil in rat blood ispresent in the literature, the present findings are in line withprevious HPLC studies (critical in forensic medicine), takinginto consideration the singular investigated drugs $(17,21,22,23)$.

Table II Validation Data for Tramadol and sildenafil

\begin{tabular}{|l|l|l|}
\hline Parameter & Tramadol & sildenafil \\
\hline Linear range $(\mu \mathrm{g} / \mathrm{mL})$ & $0.8-100$ & $0.3-100$ \\
\hline Calibration equation & $\mathrm{y}=-0.0087+0.0269 \mathrm{x}$ & $\mathrm{y}=0.778+0.0649 \mathrm{x}$ \\
\hline Correlation coefficient $(\mathrm{r} 2)$ & 0.997 & 0.997 \\
\hline Recovery $(\%)$ & $97.2 \pm 6.39$ & $100.8 \pm 5.33$ \\
\hline LOQ $(\mu \mathrm{g} / \mathrm{mL})$ & 0.8 & 0.3 \\
\hline LOD $(\mu \mathrm{g} / \mathrm{mL})$ & 0.3 & 0.1 \\
\hline Accuracy $(\%)$ & $96.6-97.8$ & $99.2-101.3$ \\
\hline Precision $(\%)$ & & \\
\hline Intra-day & $3.48-9.34$ & $5.33-11.82$ \\
\hline Inter-day & $3.8-9.12$ & $5.41-10.43$ \\
\hline Specificity & Specific & Specific \\
\hline
\end{tabular}

\section{Application of the method}

The applicability of this method was verified by determining Tramadol and Sildenafil in rat blood samples after oral administration of a combination of Tramadol and Sildenafil. HPLC analysis ofthe blood confirmed the presence of Tramadol and Sildenafil in time-related amounts (Figure 3). The amount of Tramadol and Sildenafil in blood ranged between 0.38 and $12.31 \mu \mathrm{g} / \mathrm{mL}$ and 2.3 and $9.55 \mu \mathrm{g} / \mathrm{mL}$, respectively. The described method allowed the pharmacokinetics of the four investigated drugs to be followed. Tramadol and Sildenafil had a Cmax after $1 \mathrm{~h}$. Tmax of Tramadol and Sildenafil are also in line with a recent pharmacokinetic study on rats (24). For this reason and others, because the present data have been derived using only two rats for each collection time, a large-scale study is indicated to fully determine the significance of the results. This method could also be applied to the detection of Tramadol and Sildenafil in pharmaceutical preparations. 


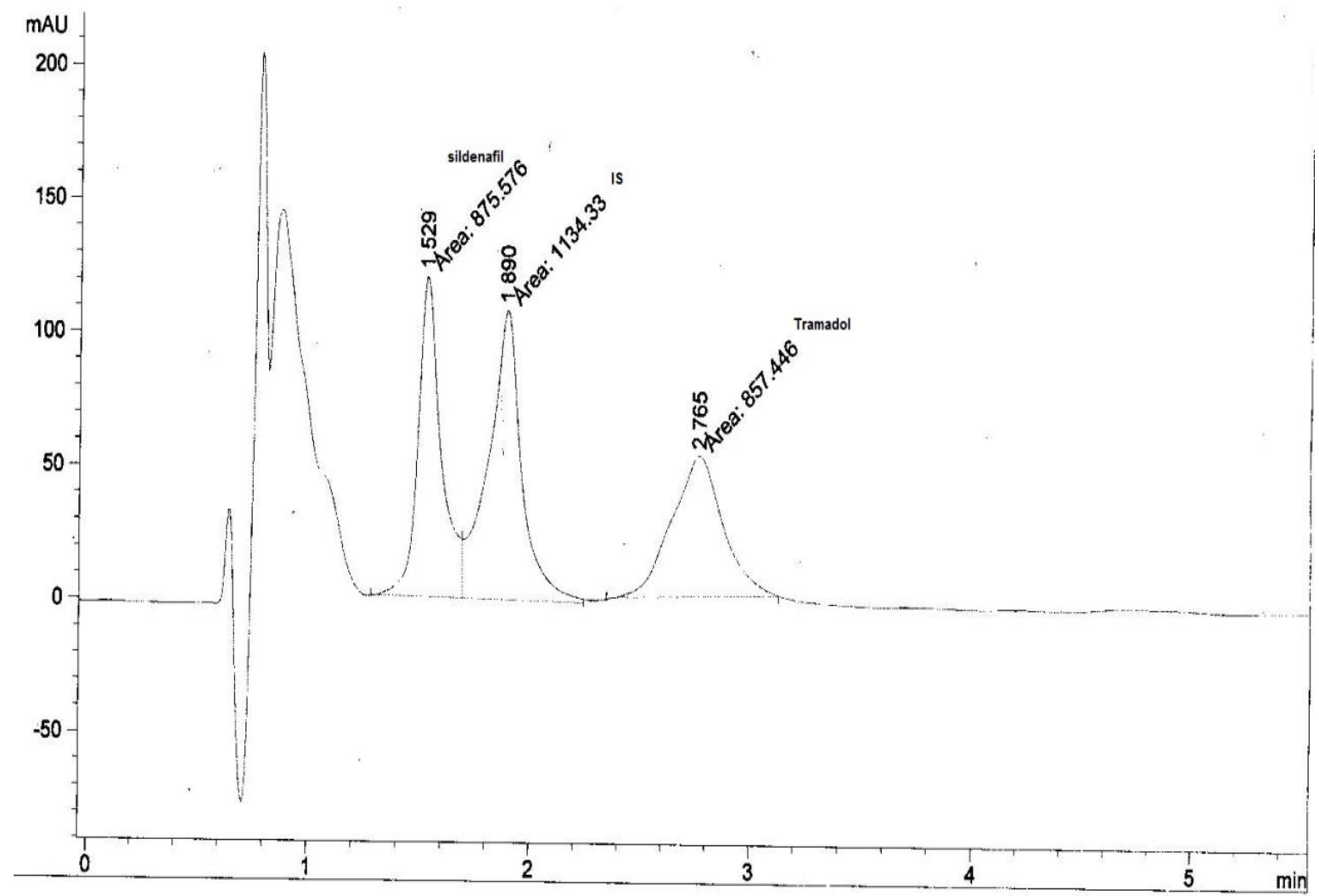

(Fig $2 \mathrm{a}$ ): chromatographic curve from pure substances and IS $(25 \mu \mathrm{g} / \mathrm{mL})$,

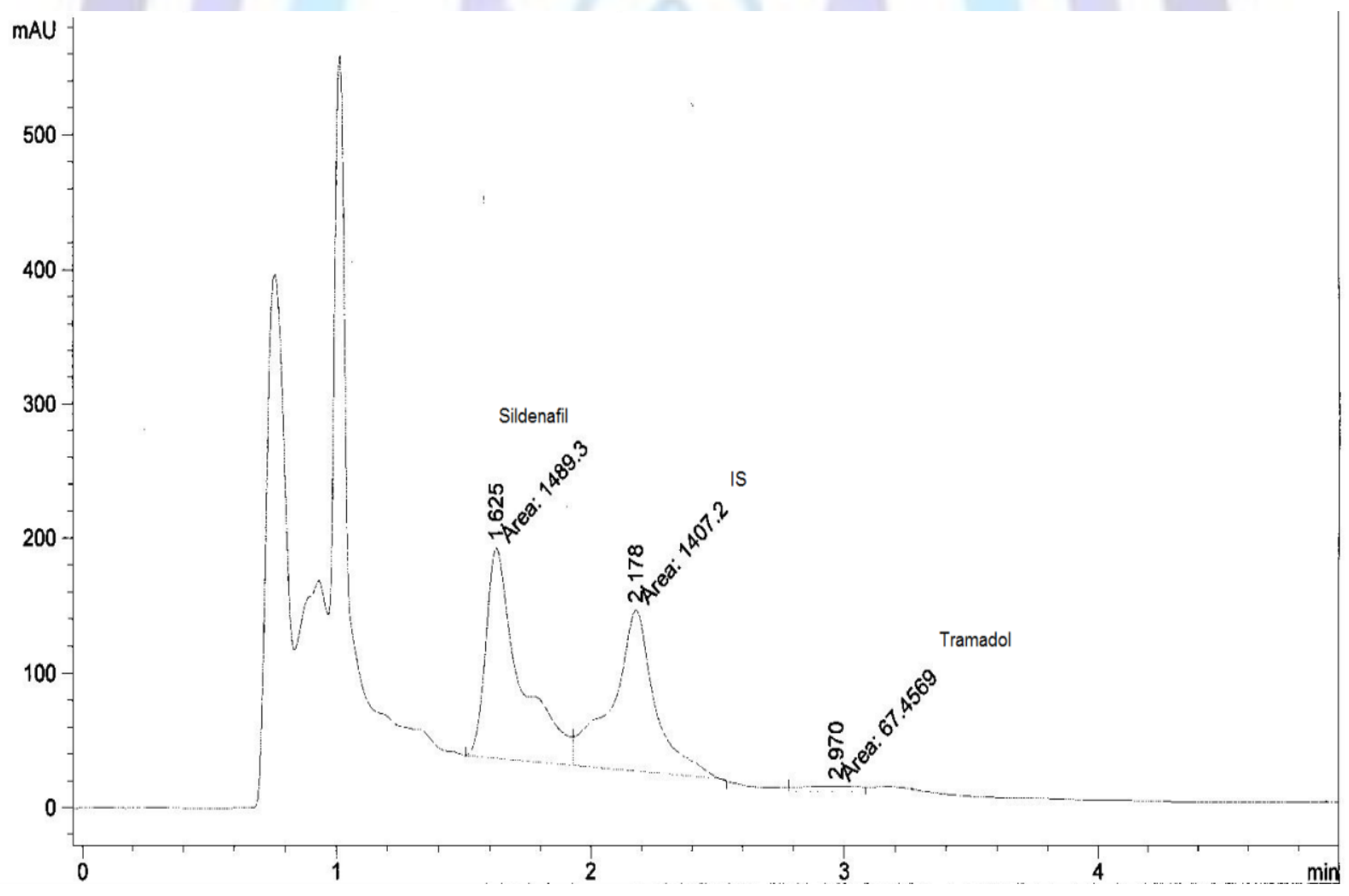

(Fig $2 \mathrm{~b}$ ): chromatographic curve from fortified sample $(2,5 \mu \mathrm{g} / \mathrm{mL})$ of Wistar rat blood 


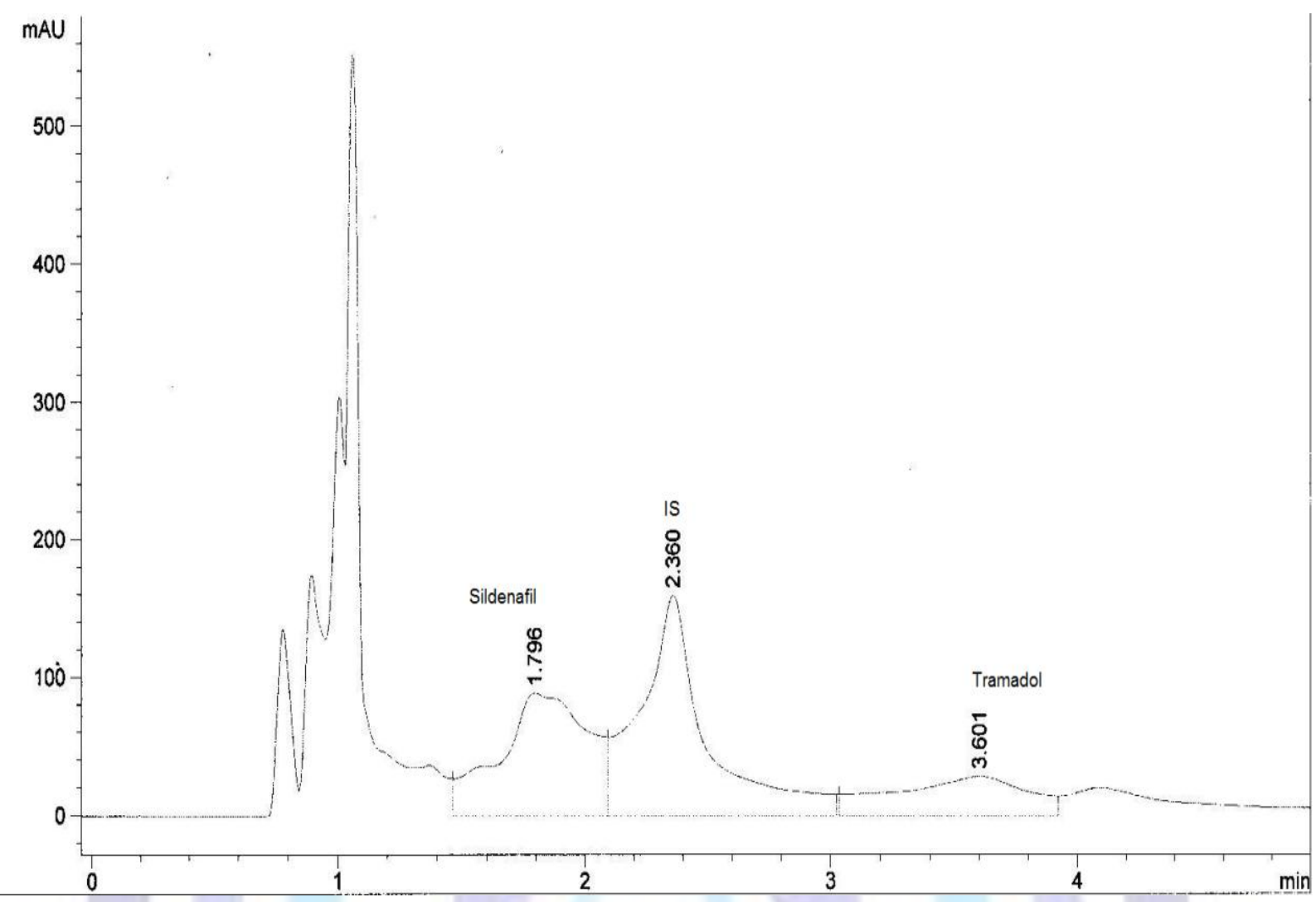

(Fig 2 c): chromatographic curve from blood sample collected from Wistar rat orally injected with a combination of tramadol (100 mg/kg) and sildenafil (100 mg/kg) (collection at $60 \mathrm{~min})$.

\section{Scatterplot of Con. ug/ml blood vs Time (h)}

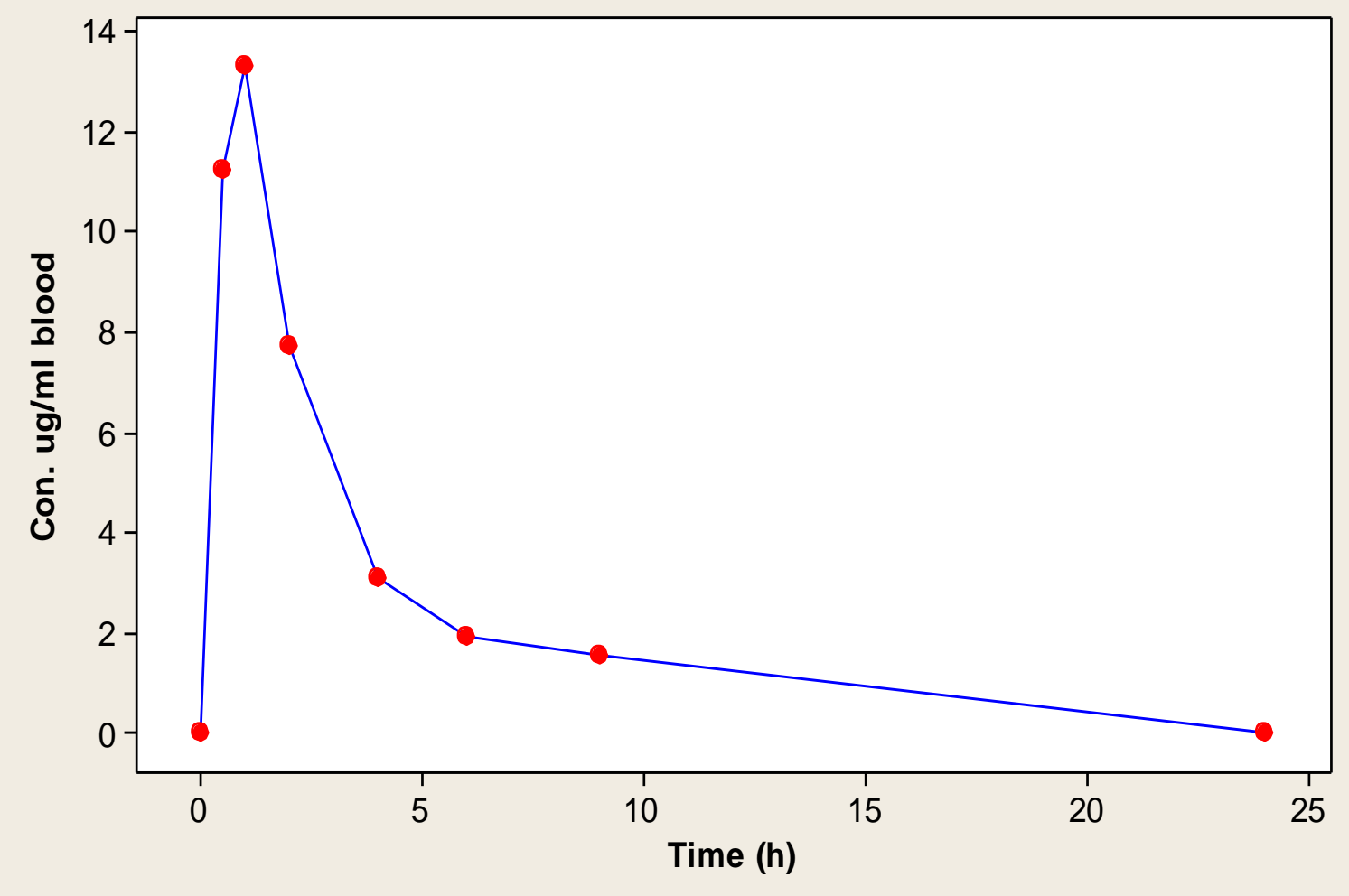

(Fig 3a) 


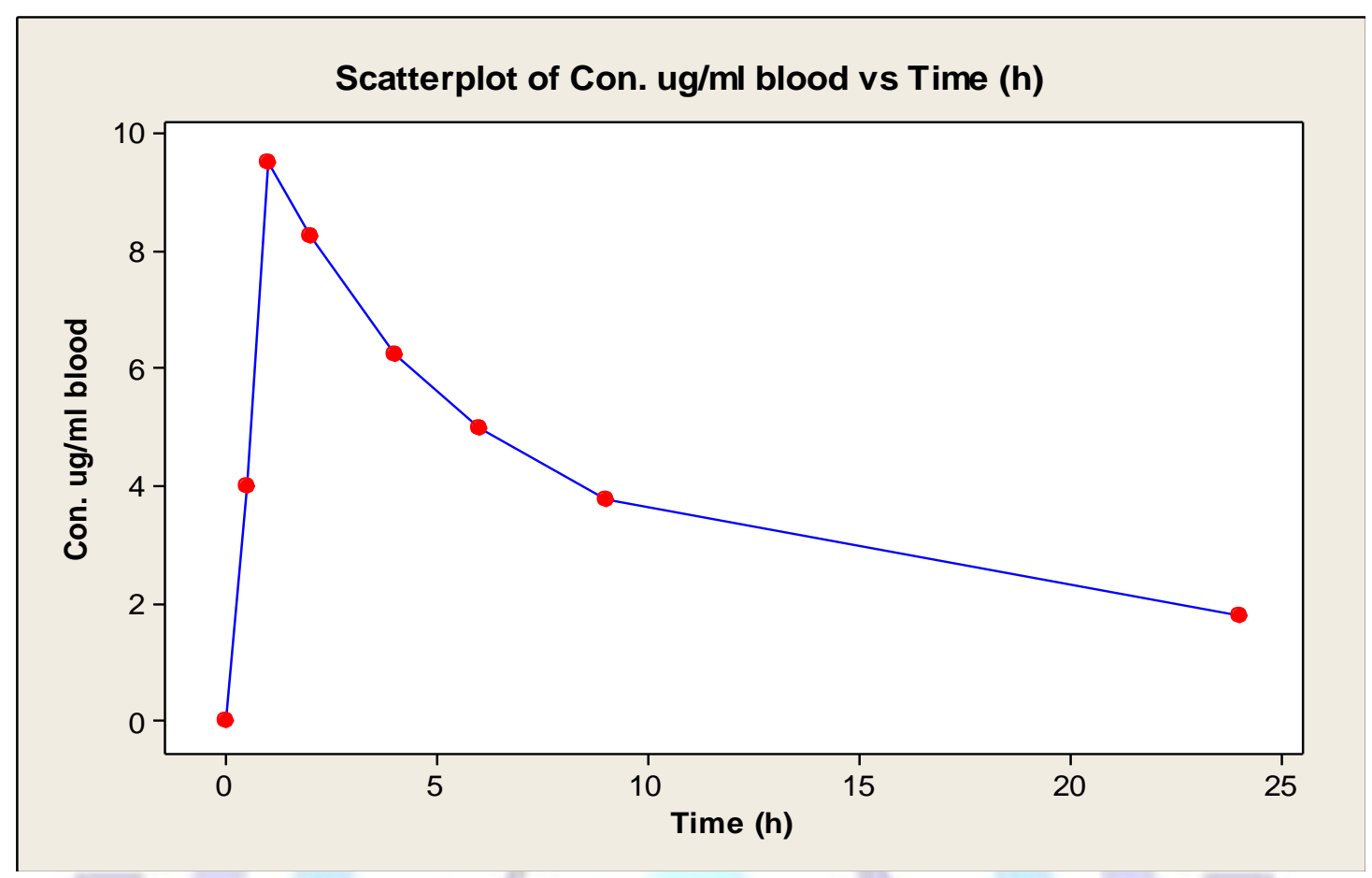

(Fig 3b)

Figure 3 a,b: HPLC analysis of the blood confirmed the presence of Tramadol and Sildenafil in time-related amounts.

\section{Conclusion}

The described analytical method provides selective and accurate determination of Tramadol and Sildenafil without the need for expensive cleanup steps, solvent-consuming flows or expensive devices. The LOQs are within acceptable limits which is matched with therapeutic does and show that the method could be useful for forensic toxicological analysis on abusers.

These features also make the described method suitable for pharmacokinetic investigations, including drug-drug interaction. In summary, this is the first time that

HPLC-UV technique has been reported to simultaneously detect of Tramadol and Sildenafil. This method (extraction, separation and applied techniques) is simple precise, accurate, and efficacious for the determination of investigated drugs in rat blood and pharmaceutical preparations.

\section{References}

[1] Raffa R. B., E. Friderichs, W. Reimann, R.P. Shank, E.E. Codd, J.L.Vaught, J. 1992.Pharmacol. Exp. Ther. 260 (1992) 275.

[2] K.S. Lewis K. S, N.H. Han. 1997. Am. J. Health Syst. Pharm. 54 (1997)643.

[3] Lintz W., H. Barth, R. Becker, E. Frankus, E. 1998. Schmidt-othelt,Arzneimittelforschung 48 (1998) 436.

[4] Budd K., R. Langford, Br. 1999.J. Anaesth. 82 (1999) 493.

[5] Gratz S. R., Flurer C. L., Wolnik K. A. 2004. Analysis of undeclared syntheticphosphodiesterase-5 inhibitors in dietary supplements and herbal matrices by LC-ESI-MS and LC-UV." J. Pharm. Biomed. Anal., 36, 525-533, 2004.

[6] Zhu, Xiao X., S., Chen, B., Zhang, F., Yao, S., Wan, Z., Yang, D., Han, J.2005. Simultaneous determination of sildenafil, vardenafil and tadalafil as forbidden components in natural dietary supplements for male sexual potency by high-performance liquid chromatography-electrospray ionization mass spectrometry" J. Chromatogr. A, 1066 (1-2), 89-95, 2005.

[7] Zou P., Oh S. S-Y., Hou, P., Low, M-Y., Koh, H-L. 2006. Simultaneous determination of synthetic phophodiesterase-5 inhibitors found in a dietary supplement and pre-mixed bulk powders for dietary supplements using high -performance liquid chromatography with diode array detection and liquid chromatography-electrospray ionization tandem mass spectrometry", J. Chromatogr. A., 1104,113-122, 2006.

[8] Dinesh N. D., Vishukumar, B. K., Nagarja, P., Made Gowda, N. M., Rangappa, K. S. 2002. Stability indicating RP LC determination of sildenafil citrate (Viagra) in pure form and inpharmaceutical samples", J. Pharm. Biomed. Anal., 29, 743748, 2002. 
[9] Lia, Chang J., T. W. 2001. Determination of transdermal sildenafil in nude mouse skin by reversed-phase highperformance liquid chromatography", J. Chromatogr. B. Biomed. Sci.Appl., 765 (2),161-166, 2001.

[10] Wang Y., Wang, J., Cui, Y., Fawcett, J.P., Gu, J. 2005.“Liquid chromatographic-tandem mass spectrometric method for the quantitation of sildenafil in human plasma", J. Chromatogr. B, 828,118-121, 2005.

[11] Sheu, Wu M. T., A.B., Yeh, G.C., Hsia, A., Ho, H.O. 2003.Development of a liquid chromatographic method for bioanalytical applications with sildenafil", J. Chromatogr. B, 791,255-262, 2003.

[12] Cho J. Y., Lim, H.S., Yu, K. S., Shim, H.J., Jang, I.J., Shin, S.G. 2003.Sensitive liquid chromatographic assay with ultraviolet detection for a new phosphodiesterase V inhibitor,DA-8159, in human plasma and urine", J. Chromatogr. B,795, 179-186, 2003.

[13]Mahmoudian M.,. 2005."Sildenafil determination in various matrices”, Iran. J. harmaco. Ther., 4,72-75, 2005.

[14] Guideline on bioanalytical method validation.2009. EMEA/CHMP/EWP/192217.

[15] Nobilis M., Pastera, J., Anzenbacher, P., Svoboda, D., Kopecky, J.,Perlik, F.; High-performance liquid chromatographic determinationof tramadol in human plasma; Journal of Chromatography B,(1996); 681: $177-183$.

[16] Kmetec V., and Ros`kar R. HPLC determination of tramadol in human breast milk. Journal of Pharmaceutical and Biomedical Analysis, 32: 1061_/1066 (2003).

[17] Mahoudian M., Hamidreza Falahtpishe H.2, Ladan Tayebil L., Moghadam E. S., and Gholamine B. 2010.DETERMINATION OF PHARMACOKINETIC PARAMETERS OF SILDENAFIL IN IRANIAN VOLUNTEERS BY AN HPLC METHOD. Turk J. Pharm. Sci. 7 (1), 69-74.

[18] Ardakani Y H.,, Rouini, M.R. 2007.Improved liquid chromatographicmethod for the simultaneous determination of tramadol and itsthree main metabolites in human plasma, urine and saliva; Journalof Pharmaceutical and Biomedical Analysis, (2007); 44:1168-1173.

[19] Nobilis M., Kopecky, J., Kventina, J., Chladek, J., Svoboda, Z.,Vorısek, V.2002. High-performance liquid chromatographic determination of tramadol and its O-desmethylated metabolite in bloodplasma. Application to a bioequivalence study in humans; Journalof Chromatography A, (2002); 949: 11-22.

[20] Rouini M.R., Ardakani, Y.H., Soltani, F., Aboul-Enein, H.Y.,Foroumadi, A.2001. Development and validation of a rapid HPLC methodfor simultaneous determination of tramadol, and its two main metabolitesin human plasma; Journal ofChromatography B, (2006);830: 207-211.

[21] Tao,Stone Q., D.J., Jr., Borenstein, M.R., Jean-Bart, V., Codd, E.E.,Coogan, T.P., etc.2001. Gas chromatographic method using nitrogenphosphorusdetection for the measurement of tramadol and itsO-desmethyl metabolite in plasma and brain tissue of mice andrats; Journal of Chromatography B, (2001); 763: 165-171.

[22] Moeller M.R., Steinmeyer, S., Kraemer, T.1998. Determination of drugs ofabuse in blood; Journal of Chromatography B, (1998); 713:91-109.

[23] Nobilis M., Pastera, J., Anzenbacher, P., Svoboda, D., Kopecky, J.,Perlik, F.1996. High-performance liquid chromatographic determinationof tramadol in human plasma; Journal of Chromatography B,(1996); 681: 177-183.

[24] Godoy A. L., De Moraes, N.V., Martinez, E.Z., Carvalho, T.M.,Marques, M.P., Lanchote, V.L.2011.Simultaneous analysis of tramadol,O-desmethyltramadol, and $\mathrm{N}$-desmethyltramadol enantiomers in ratplasma by high-performance liquid chromatography-tandem massspectrometry: Application to pharmacokinetics; Chirality, (2011);23: $287-293$. 